\title{
Erkek Judocu ve Haltercilerin Bazı Fiziksel ve Fizyolojik Bulgularının İncelenmesi
}

\author{
Nazmi SARITAŞ ${ }^{1} \quad$ Ümit HAYTA ${ }^{2} \quad$ Mustafa KAYA $^{1}$ \\ ${ }^{1}$ Erciyes Üniversitesi, Spor Bilimleri Fakültesi, KAYSERI \\ ${ }^{2}$ Manisa Celal Bayar Üniversitesi Spor Bilimleri Fakültesi, MANISA
}

Künye: Sarıtaş, N., Hayta, Ü. ve Kaya, M. (2018). Erkek Judocu ve Haltercilerin Bazı Fiziksel ve Fizyolojik Bulgularının İncelenmesi. Gaziantep Üniversitesi Spor Bilimleri Dergisi, 3(4): 200-211.

\section{Öz}

Bu çalışmada, erkek judocu ve haltercilerin bazı fiziksel ve fizyolojik bulgularının karşılaştırılması amaçlanmıştır. Çalışmaya 52 judocu ve 88 halterci olmak üzere toplamda 140 gönüllü erkek sporcu katılmıştır. Çalışmaya katılan gönüllülerin vücut ağırlıkları, beden kitle indeksi, vücut yağ yüzdesi, toplam vücut sıvısı ölçümleri alındı. Ayrıca gönüllülerin el kavrama kuvveti, oksijen saturasyonu, dinlenik nabızları, sistolik ve diastolik kan basınçları ölçüldü, relatif el kavrama kuvvetleri hesaplandı. Verilerin karşılaştırılmasında bağımsız gruplarda testi uygulandı. Judocu ve haltercilerin boy uzunlukları, vücut yağ yüzdeleri ve oksijen saturasyonları arasında fark bulundu $(p<0.05)$. Sonuç olarak, haltercilerin boylarının judoculara göre kısa olması ve vücut yağ yüzdelerinin fazla olması halter branşına özgü bir özellik olmasından kaynaklandığını düşünmekteyiz. Ayrıca fiziksel ve fizyolojik parametrelerin bir birine yakın olmasında spor branşlarının kendi içinde sıkletlere ayrılmasından kaynaklandığını düşünülmektedir. Yaptığımız çalışmada elde edilen veriler literatürdeki benzer çalışmalar ile karşılaştırıldığında çalışma sonuçlarımız ile benzerlik görülmüştür.

\section{Orijinal Makale}

Yayın Bilgileri

Gönderi Tarihi: 07.11.2018

Kabul Tarihi: 24.12 .2018

Yayın Tarihi: 28.12.2018

Sorumlu Yazar

e-mail: nsaritas@gmail.com

DOI: 10.31680/gaunjss.479904

Anahtar Kelimeler: Judo, Halter, Bi̇A, Fiziki parametreler, Fizyolojik parametreler

\section{Examination of Some Physical and Physiological Findings of Male Judoka and Weightlifters in Individual Sports}

\begin{abstract}
In this study, it is aimed to compare some physical and physiological findings of judo and weightlifters. A total of 140 volunteers, 52 judoka and 88 weightlifters, participated in the study. Volunteers who participated in this study were taken body weights, body mass index, body fat percentage, total body fluid measurements. In addition volunteers' hand grip strength, oxygen saturation, resting pulse, systolic and diastolic blood pressures were measured and relative hand-grip forces. Independent groups were t-tested for comparison of data. Judo and weightlifters had differences in height length, body fat percentage and oxygen saturation $(p<0.05)$. As a result; We think that the weight of the weightlifters is shorter than the judoka and that the body fat percentage is higher than that of weightlifting. In addition, physical and physiological parameters are close to each other because of the branches of sports branches are thought to be divided into. The data obtained in our study compared with the similar studies in the literature compared with the data was similar.
\end{abstract}

Key Words: Weightlifting, Judo, BIA, Physical parameters, Physiological parameters

\section{Original Article}

Article Info

Received: 07.11.2018

Accepted: 24.12 .2018

Published: 28.12 .2018

Corresponding Author

e-mail: nsaritas@gmail.com 


\section{Giriş}

Vücut kompozisyonu çalışmalarında biyoimpedans analizi (BİA) kullanımına giderek artan bir ilgi vardır (Chumlea ve Guo, 1994). Vücut bileşimindeki değişiklikler; boy, vücut kütle ve vücut kitle indeksi ergenlik döneminde her iki cinste de artar (Siervogel ve ark., 2003). Biyoelektrik impedans analizi, direnç $(R)$ ve reaktans'nin (Xc) saf değerleri, hücresel sağlık / fonksiyonun göstergesi olan ve fonksiyonel durum ve hastalıkla prognoz bozukluğu ile ilişkili faz açısını belirlemek için kullanılır (Fukuda ve ark., 2016). BİA uygulaması kolay, ucuz, çok zaman almayan bir yöntem olduğundan vücut kompozisyonunun ölçümlerini tespit etmek için klinikte ve spor bilimlerinde yaygın olarak kullanılan bir yöntemdir (Küçükkubaş ve ark., 2006; Nunez ve ark., 2003). Biyoelektrik impedans analizi, eller ve ayaklar gibi temas noktaları arasında geçen ağrısız bir elektrik akımı kullanarak vücudun direncini ve reaktansını (impedansı) ölçer. Akım hızı, üretici tarafından belirlenen özel denklemleri kullanarak vücut yağ yüzdesi ve serbest yağ kütlesi tahminlerine dönüştürülür (Esco ve ark., 2015). BİA yağ dokunun su içermediği ve yağ harici dokularda su miktarının sabit olduğu varsayımına dayanır. BİA yönteminde vücuttan elektrik akımı geçtiğinde, iki elektrot arasında oluşan voltaj düşüklüğü (farkı), vücudun o bölgesindeki vücut sıvısının hacmine bağlıdır. Voltaj düşüklüğünün ölçülmesi sonucunda direnç hesaplanır. İmpedans yumuşak dokunun elektriksel iyon iletim özelliği ile ölçülür. Elektrik akımına karşı oluşan direnç, toplam vücut suyu ve elektrolitlerin dağılımı ile ters orantılıdır (Wang ve ark.,1999; Akt.Harbili ve ark., 2008).

İleri multi frekans BİA cihazları intra ve ekstraselüler alanlar vasıtasıyla çok çeşitli frekansları geçmektedir. Buna ek olarak, çok frekanslı BİA insan vücudundaki 5 farklı silindir arasında empedansı ayrı ayrı ölçme yeteneğine sahiptir. Bu, vücut boyunca ve kollar, bacaklar ve gövde gibi çeşitli segmentlerdeki yağsız yumuşak dokunun analiz edilmesine olanak tanır. BİA'nın dezavantajı, nemlendirme durumuna, uygun deri hazırlama gereksinimine ve elektrotların hassas yerleştirilmesine bağlı olması ile ilgilidir. Bununla birlikte, teknik basitlik nedeniyle BİA yönteminin yaygınlığı atletik şartlandırma ve spor beslenme programları içinde artmaktadır (Esco ve ark., 2015).

Modern Tıp'ta kullanılan pulse oksimetre, kandaki oksijen satürasyonunun ölçülmesine yarayan, kalibrasyon gerektirmeyen bir araçtır (Pole, 2002). Pulse oksimetre, arteriyel kanda oksijenle yüklü hemoglobin yüzdesini belirlemekte olup bu yolla elde edilen bulgu fonksiyonel oksijen saturasyonu olarak bilinmektedir (Grap, 
2002). Kan basıncı ölçümünün genel kardiovasküler durumun belirlenmesinde taşıdığı önem vazgeçilmez nitelik taşımaktadır (Mille ve ark., 2005). Kardiyovasküler faktörler fiziksel uygunluğun temel belirleyicisidir (MacAuley ve ark.,1999).

Kavrama birçok günlük aktivite için kritik olduğundan, genel olarak fiziksel güç ve sağlığın bir göstergesi olarak kavrama gücü genellikle klinik ortamlarda kullanııır. (Boissy ve ark., 1999). Ayrıca, farklı spor oyunlarında topu yakalamak ve fırlatma(Nag ve ark., 2003), güreş, judo ve kaya tırmanışı gibi kavrama sporlarında kavrama kuvveti çok önemlidir (Leyk ve ark., 2007; Watts ve ark., 2003). Bu çalışmada; judocular ve haltercilerin bazı fiziksel ve fizyolojik parametrelerin karşılaştırılması amaçlanmıştır.

\section{Yöntem}

Çalışmaya 88 halterci ve 52 judocu olmak üzere toplamda 140 gönüllü katılmıştır. Çalışmada, halterciler ve judocuların ölçümleri Erciyes Üniversitesi spor salonunda müsabaka öncesi alındı. Çalışmaya katılan gönülülerin vücut ağırlıkları, beden kitle indeksi, vücut yağ yüzdesi, toplam vücut sıvısı ölçümleri Tanita BC 418 marka cihazla ölçüldü. Ayrıca gönüllülerin el el kavrama kuvveti, $\mathrm{O}_{2}$ saturasyonu, nabızları, sistolik ve diastolik kan basınçları, el kavrama kuvvetleri ölçüldü, sağ ve sol el kavrama kuvvetlerinin vücut ağırlığına bölünmesiyle relatif el kavrama kuvvetleri hesaplandı.

\section{Kan Basıncı ve Nabız Ölçümü}

Gönüllülerin kan basınçları dijital göstergeli, el pompalı, klasik koldan sarmalı tansiyon aleti ile ölçülmüştür. Ölçümler bütün deneklerin sol kolundan ve dinlenik durumdayken alınmıştır. Sistolik, diastolik kan basınçları ve nabızları sporcu değerlendirme formuna kaydedilmiştir.

\section{Oksijen Saturasyonu Ölçümü}

Deneklerin oksijen saturasyonları, pulse oksimetre cihazı ile ölçülmüştür. Deneklerin sol el işaret parmaklarından ölçümler alınmıştır. Dijital ekrandan okunan değer sporcu değerlendirme formuna yazılmıştır. 


\section{Biyoelektrik İmpedans Analizi Ölçümü}

BİA yağ dokunun su içermediği ve yağ harici dokularda su miktarının sabit olduğu varsayımına dayanır. BİA yönteminde vücuttan elektrik akımı geçtiğinde, iki elektrot arasında oluşan voltaj düşüklüğü (farkı), vücudun o bölgesindeki vücut sıvısının hacmine bağlıdır. Voltaj düşüklüğünün ölçülmesi sonucunda direnç (impedans) hesaplanır. İmpedans yumuşak dokunun elektriksel iyon iletim özelliği ile ölçülür. Elektrik akımına karşı oluşan direnç, toplam vücut sıvısı ve elektrolitlerin dağılımı ile ters orantııdır (Wang ve ark 1999; Akt. Harbili ve ark., 2008). Biyoelektrik impedans analizi ölçümü "Tanita - BC 418 MA (Tanita corporation, Tokyo-Japonya) cihazı ile yapıldı. Tanita cihazı 8 elektrotlu olup, yüksek frekanslı sabit akım kaynağını kullanmaktadır (Çalışkan, 2007).

Ölçüme katılan bireylerde, ölçümden en az 4 saat öncesine kadar hiçbir şey yememeleri, kafein içeren içecekler de dâhil olmak üzere bir şey içmemeleri, sauna veya banyoya girmemiş olmaları, antrenman süresince gönüllülerin alkol tüketmemeleri ve ölçümün yapılacağı gün spor yapmamaları şartları arandı. Öıçüm yapılırken bireylerden, cihazın metal yüzeyinde çıplak ayak üzerinde durmaları, bir yandan da her iki elleriyle cihazın elle tutulması gereken parçalarını tutmaları ve kollarını gövdeye paralel olarak serbest bırakmaları istendi. Ölçümler her gönüllü için yaklaşık 1-2 dakika kadar sürmüş olup, biyoelektrik impedans analiz cihazı ile saptanan değerler cihazdan çıktı olarak alındı.

\section{Kavrama Kuvveti Ölçümü}

Kavrama kuvveti parametrelerini ölçmek için Holtain marka el dinamometresi kullanıldı. El dinamometresi deneğin el ölçülerine göre ayarlandı, denek dirseğini bükmeden kolu düz ve omuzdan 10-15'lik bir açı yapacak şekilde yan tarafta iken eli ile mümkün olduğunca fazla dinamometreyi sıkmaya çalışmıştır. Deneğin her iki eliyle 2 denemeden sonra en iyi performansı belirlendi. Dinamometre her denemeden sonra sıfırlandı, değerlendirmeye en iyi olan performans alındı.

\section{İstatistiksel Analiz}

Yapılan bu çalışmada verilerin istatistiksel analizinde SPSS 20.0 paket programı kullanıldı. Verilerin gösteriminde aritmetik ortalama ve standart hata ile gösterildi. Dağııımın normalliği Kolmogorov-Smirnov testi ile test edildi. Dağılımların normal dağıldığı tespit edildikten sonra bağımsız gruplarda $t$ testi ile grup 
karşılaştırmaları yapıldı. Ayrıca değişkenler arasındaki ilişkiler pearson korelasyon analizi ile yapıldı. Anlamlılık düzeyi $(p<0.05)$ alındı.

\section{Bulgular}

Tablo 1. Erkek judo ve halter sporcularının fiziksel karakteristiklerinin karşılaştırılması

\begin{tabular}{|c|c|c|c|c|c|}
\hline Değişken & Grup & $\mathbf{n}$ & $X \pm S D$ & $\mathbf{t}$ & $\mathbf{p}$ \\
\hline \multirow{2}{*}{ Yaş (Yıl) } & Halter & 88 & $20.15 \pm 4.26$ & \multirow{2}{*}{-1.586} & \multirow{2}{*}{0.115} \\
\hline & Judo & 52 & $21.08 \pm 2.67$ & & \\
\hline \multirow{2}{*}{ Boy uzunluğu (cm) } & Halter & 88 & $171.59 \pm 7.87$ & \multirow{2}{*}{-2.975} & \multirow{2}{*}{$0.003^{* *}$} \\
\hline & Judo & 52 & $175.58 \pm 7.29$ & & \\
\hline \multirow{2}{*}{ Vücut ağırlığı (kg) } & Halter & 88 & $76.38 \pm 16.49$ & \multirow{2}{*}{-0.422} & \multirow{2}{*}{0.674} \\
\hline & Judo & 52 & $77.67 \pm 19.17$ & & \\
\hline \multirow{2}{*}{ VKI $\left(\mathrm{kg} / \mathrm{m}^{2}\right)$} & Halter & 88 & $25.86 \pm 4.41$ & \multirow{2}{*}{1.164} & \multirow{2}{*}{0.247} \\
\hline & Judo & 52 & $24.95 \pm 4.50$ & & \\
\hline \multirow{2}{*}{ BMO (kcal) } & Halter & 88 & $1993.16 \pm 302.83$ & \multirow{2}{*}{-0.814} & \multirow{2}{*}{0.417} \\
\hline & Judo & 52 & $2041.52 \pm 394.47$ & & \\
\hline \multirow{2}{*}{ Vücut yağ yüzdesi (\%) } & Halter & 88 & $13.07 \pm 6.26$ & \multirow{2}{*}{2.552} & \multirow{2}{*}{$0.012^{*}$} \\
\hline & Judo & 52 & $10.15 \pm 6.96$ & & \\
\hline \multirow{2}{*}{ Vücut yağ ağırlığı (kg) } & Halter & 88 & $10.74 \pm 7.19$ & \multirow{2}{*}{1.414} & \multirow{2}{*}{0.160} \\
\hline & Judo & 52 & $8.79 \pm 8.93$ & & \\
\hline \multirow{2}{*}{ Yağsız vücut ağırlığı (kg) } & Halter & 88 & $65.75 \pm 10.78$ & \multirow{2}{*}{-1.579} & \multirow{2}{*}{0.117} \\
\hline & Judo & 52 & $68.86 \pm 12.05$ & & \\
\hline \multirow{2}{*}{ Toplam vücut sıvısı (kg) } & Halter & 88 & $48.25 \pm 8.04$ & \multirow{2}{*}{-1.481} & \multirow{2}{*}{0.141} \\
\hline & Judo & 52 & $50.41 \pm 8.82$ & & \\
\hline
\end{tabular}

VKI: vücut kitle indeksi, BMO: Bazal metabolik oran

Judocu ve haltercilerin boy uzunluğu, vücut yağ yüzdesi değerlerinde anlamlı farklılık bulunurken ( $p<0.05)$, yağsız vücut kitlesi ve toplam vücut sıvısı vücut ağırlığı, beden kitle indeksi, bazal metabolizma hızı ve yağ kütlesi parametrelerinde anlamlı bir farklılık tespit edilmedi ( $p>0.05)$ (Tablo 1$)$.

Tablo 2. Erkek judo ve haltercilerin bazı fiziksel ve fizyolojik bulgularının karşılaştırılması

\begin{tabular}{|c|c|c|c|c|c|}
\hline Değişken & Grup & $\mathbf{n}$ & $\mathrm{X} \pm \mathrm{SD}$ & $\mathbf{t}$ & $\mathbf{p}$ \\
\hline \multirow{2}{*}{ Sağ el kavrama kuvveti (kg) } & Halter & 88 & $43.92 \pm 11.47$ & \multirow{2}{*}{-1.278} & \multirow{2}{*}{0.203} \\
\hline & Judo & 52 & $46.47 \pm 11.31$ & & \\
\hline \multirow{2}{*}{ Sol el kavrama kuvveti (kg) } & Halter & 88 & $43.91 \pm 11.51$ & \multirow{2}{*}{-1.591} & \multirow{2}{*}{0.114} \\
\hline & Judo & 52 & $46.98 \pm 10.12$ & & \\
\hline \multirow{2}{*}{$\begin{array}{l}\text { Sağ el relatif kavrama kuvveti } \\
(\mathrm{kg})\end{array}$} & Halter & 88 & $0.59 \pm 0.18$ & \multirow{2}{*}{-0.910} & \multirow{2}{*}{0.365} \\
\hline & Judo & 52 & $0.62 \pm 0.19$ & & \\
\hline \multirow{2}{*}{ Sol el relatif kavrama kuvveti $(\mathrm{kg})$} & Halter & 88 & $0.59 \pm 0.19$ & \multirow{2}{*}{-1.170} & \multirow{2}{*}{0.244} \\
\hline & Judo & 52 & $0.63 \pm 0.19$ & & \\
\hline \multirow{2}{*}{ Oksijen saturasyonu (\%) } & Halter & 88 & $96.09 \pm 1.80$ & \multirow{2}{*}{2.069} & \multirow{2}{*}{$0.040^{*}$} \\
\hline & Judo & 52 & $95.42 \pm 1.92$ & & \\
\hline \multirow{2}{*}{ Nabız (atım/dak) } & Halter & 88 & $88.36 \pm 14.27$ & \multirow{2}{*}{-1.266} & \multirow{2}{*}{0.208} \\
\hline & Judo & 52 & $91.63 \pm 15.60$ & & \\
\hline Sistolik kan basıncı (mmHg) & Halter & 88 & $117.32 \pm 12.50$ & 0.392 & 0.696 \\
\hline
\end{tabular}




\begin{tabular}{llllll}
\hline & Judo & 52 & $116.19 \pm 18.35$ & & \\
Diastolik kan basıncı (mmHg) & Halter & 88 & $71.45 \pm 10.32$ & \multirow{2}{*}{0.696} & 0.488 \\
& Judo & 52 & $70.10 \pm 12.48$ & & \\
\hline
\end{tabular}

Judocu ve haltercileri sporcuların oksijen saturasyonu anlamlı farklılık tespit edilirken $(p<0.05)$, sağ ve sol el el kavrama kuvvetlerinde sağ ve sol el relatif el kavrama kuvvetlerinde, nabız, sistolik ve diastolik kan basıncı değerlerinde anlamlı farklılık bulunmadı ( $p>0.05)$. (Tablo 2).

Tablo 3. Erkek Judocu ve haltercilerin fiziksel durumları arasındaki ilişkiler $(n=140)$

\begin{tabular}{|c|c|c|c|c|c|c|c|c|c|}
\hline Değiş̧kenler & & $\begin{array}{c}\mathrm{BMI} \\
(\mathrm{kgm} 2)\end{array}$ & $\begin{array}{c}\text { Vücut } \\
\text { yağ } \\
\text { yüzdesi } \\
(\%)\end{array}$ & $\begin{array}{c}\text { Vücut } \\
\text { yağ } \\
\text { kitlesi } \\
(\mathrm{kg})\end{array}$ & $\begin{array}{c}\text { Yağsız } \\
\text { vücut } \\
\text { ağırlığı } \\
(\mathrm{kg})\end{array}$ & $\begin{array}{c}\text { Toplam } \\
\text { vücut } \\
\text { sIvIsI } \\
(\mathrm{kg}) \\
\end{array}$ & $\begin{array}{c}\text { Sağ el } \\
\text { el } \\
\text { kavrama } \\
\text { kuvveti } \\
(\mathrm{kg})\end{array}$ & $\begin{array}{c}\text { Sol el el } \\
\text { kavrama } \\
\text { kuvveti } \\
(\mathrm{kg})\end{array}$ & $\begin{array}{c}\text { Sağ el } \\
\text { relatif el } \\
\text { kavrama } \\
\text { kuvveti }\end{array}$ \\
\hline \multirow{2}{*}{ Vücut yağ yüzdesi (\%) } & $r$ & $0.796^{\star *}$ & & & & & & & \\
\hline & $\mathrm{p}$ & 0.000 & & & & & & & \\
\hline \multirow{2}{*}{ Vücut yağ kitlesi (kg) } & $r$ & $0.902^{* *}$ & $0.935^{* *}$ & & & & & & \\
\hline & $\mathrm{p}$ & 0.000 & 0.000 & & & & & & \\
\hline \multirow{2}{*}{ Yağsız vücut ağırlığı (kg) } & $r$ & $0.793^{* *}$ & $0.407^{\star *}$ & $0.639^{\star *}$ & & & & & \\
\hline & $\mathrm{p}$ & 0.000 & 0.000 & 0.000 & & & & & \\
\hline \multirow{2}{*}{ Toplam vücut sıvısı (kg) } & $r$ & $0.789^{* *}$ & $0.411^{\star *}$ & $0.640^{* *}$ & $0.995^{* *}$ & & & & \\
\hline & $\mathrm{p}$ & 0.000 & 0.000 & 0.000 & 0.000 & & & & \\
\hline \multirow{2}{*}{$\begin{array}{l}\text { Sağ el el kavrama } \\
\text { kuvveti (kg) }\end{array}$} & $r$ & 0.147 & 0.015 & 0.084 & $0.197^{\star}$ & $0.184^{*}$ & & & \\
\hline & $\mathrm{p}$ & 0.082 & 0.864 & 0.321 & 0.019 & 0.029 & & & \\
\hline \multirow{2}{*}{$\begin{array}{l}\text { Sol el kavrama kuvveti } \\
(\mathrm{kg})\end{array}$} & $r$ & 0.132 & 0.005 & 0.067 & 0.165 & 0.150 & $0.917^{\star \star}$ & & \\
\hline & $\mathrm{p}$ & 0.119 & 0.955 & 0.433 & 0.052 & 0.077 & 0.000 & & \\
\hline \multirow{2}{*}{$\begin{array}{l}\text { Sağ el relatif kavrama } \\
\text { kuvveti }\end{array}$} & $r$ & $-0.483^{* *}$ & $-0.426^{* *}$ & $-0.460^{* *}$ & $-0.463^{* *}$ & $-0.471^{* *}$ & $0.732^{* *}$ & $0.690^{* *}$ & \\
\hline & $\mathrm{p}$ & 0.000 & 0.000 & 0.000 & 0.000 & 0.000 & 0.000 & 0.000 & \\
\hline \multirow{2}{*}{$\begin{array}{l}\text { Sol el relatif kavrama } \\
\text { kuvveti }\end{array}$} & r & $-0.493^{* *}$ & $-0.425^{* *}$ & $-0.467^{* *}$ & $-0.491^{* *}$ & $-0.500^{* \star}$ & $0.631^{* *}$ & $0.732^{* *}$ & $0.936^{* *}$ \\
\hline & $\mathrm{p}$ & 0.000 & 0.000 & 0.000 & 0.000 & 0.000 & 0.000 & 0.000 & 0.000 \\
\hline
\end{tabular}

Judocu ve haltercilerin toplamda bazı fiziksel bulgular arasındaki ilişkilerden vücut yağ yüzdesi ile BKI, vücut yağ kitlesi, yağsız vücut ağırlığı, toplam vücut sıvısı ile pozitif yönde istatistiksel olarak anlamlı ilişki bulundu $(p<0.001)$. Vücut yağ yüzdesi ile sağ ve sol el relatif el kavrama kuvvetleri arasında negatif yönde istatistiksel olarak anlamlı ilişki meydana gelmiştir $(p<0.001)$. Vücut yağ kitlesi ile yağsız vücut ağırlığı, toplam vücut sıvısı arasında pozitif yönde istatistiksel olarak anlamlı ilişki görülürken $(p<0.001)$, vücut yağ kitlesi ile sağ ve sol el relatif el kavrama kuvvetleri arasında negatif yönde istatistiksel olarak anlamlı ilişki meydana geldi $(p<0.001)$. Toplam vücut sıvısı ile sağ ve sol el relatif el kavrama kuvvetleri arasında negatif yönde istatistiksel olarak anlamlı ilişki meydana geldi $(p<0.001)$. 


\section{Tartışma ve Sonuç}

$\mathrm{Bu}$ çalışmada; Judocu ve haltercilerin boy uzunluğu, vücut yağ yüzdesi değerlerinde anlamlı farklılık bulunurken, yağsız vücut kitlesi ve toplam vücut sıvısı vücut ağırlığı, beden kitle indeksi, bazal metabolizma hızı ve yağ kütlesi parametrelerinde anlamlı bir farklılık tespit edilmedi. Ayrıca judocu ve haltercileri sporcuların oksijen saturasyonu anlamlı farklılık tespit edilirken, sağ ve sol el el kavrama kuvvetlerinde sağ ve sol el relatif el kavrama kuvvetlerinde, nabız, sistolik ve diastolik kan basıncı değerlerinde anlamlı farklılık bulunmadı. Judocu ve haltercilerin toplamda bazı fiziksel bulgular arasındaki ilişkilerden vücut yağ yüzdesi ile BKİ, vücut yağ kitlesi, yağsız vücut ağırlığı, toplam vücut sıvısı ile pozitif yönde istatistiksel olarak anlamlı ilişki bulunurken, vücut yağ yüzdesi ile sağ ve sol el relatif el kavrama kuvvetleri arasında negatif yönde istatistiksel olarak anlamlı ilişki meydana gelmiştir. Vücut yağ kitlesi ile yağsız vücut ağırlığı, toplam vücut sıvısı arasında pozitif yönde istatistiksel olarak anlamlı ilişki görülürken, vücut yağ kitlesi ile sağ ve sol el relatif el kavrama kuvvetleri arasında negatif yönde istatistiksel olarak anlamlı ilişki meydana geldi. Toplam vücut sıvısı ile sağ ve sol el relatif el kavrama kuvvetleri arasında negatif yönde istatistiksel olarak anlamlı ilişki meydana gelmiştir.

Literatür incelendiğinde Halterciler üzerinde yapılan bir çalışmada yaş $24.65 \pm 2.084$ yıl, boy $173.420 \pm 2.084 \mathrm{~cm}$, vücut ağırlığı $80.08 \pm 7.65 \mathrm{~kg}$ ve vücut yağ yüzdesi \% 8.128 \pm 2.17 olarak hesaplamıştır (Akkuş, 1994). Judocular üzerinde yapılan çalışmalarda judocuların boy $178 \pm 0.06 \mathrm{~cm}$, olarak hesaplamıştır (Tutkun, 1996). Benzer şekilde Belçika milli takımındaki 24 elit judocunun boyları ortalamasını $175.2 \pm 7.3 \mathrm{~cm}$ olarak bildirmişlerdir (Claessens ve ark., 1984). Elit Türk judocularının boylan ortalamasını $176.27 \pm 7.27 \mathrm{~cm}$ olarak bildirmiştir (Aydın, 1997). Çalışmamızda halter sporcularının judocularına göre daha kısa olarak tespit edilmiştir. Halter sporunda yer çekimine karşı yapılan iş azaltmak bakımından sporcuların boyları kısa seçilirken, judo sporunda böyle bir durum olmadığı için iki spor arasında boy farkının haltercilerin spor branşının bir gereği olarak kısa boylu sporculardan oluşmasından kaynaklandığını düşünmekteyiz.

Haltercilerin vücut yağ yüzdesi değerlerini \% 9.8 olarak hesaplamışlardır (Lukaski, ve ark.,1986). Sarıtaş'ın (1995), ümitler kategorisindeki 15 judocu üzerine yaptığı çalışmada sporcuların vücut yağ yüzdesi ortalamasını 8.44\$1.18 olarak bildirmiştir. Bu değerlere bakıldığında çalışmaya katılan haltercilerinin vücut yağı bakımından daha fazla değerlere sahip olduğu görülmektedir. Türk Milli Haltercileri 
üzerine yapılan araştırmada vücut yağ yüzdesini 13.8 ve yağsız vücut kitlesinin yüzdesi ise 86.2 olarak hesaplanmıştır (Turnagöl ve Demirel, 1992). Yine halterciler üzerinde yapılan araştırmada vücut yağ yüzdesini \%16.8 ve yağsız vücut kitlesi \% 83.2 olarak hesaplamıştır (Akın ve ark., 2004). Kuru ve Cicioğlu'nun (2000) 5. Uluslararası Boğaziçi Judo Turnuvası'na katılan judocular üzerinde yaptığı çalışmada

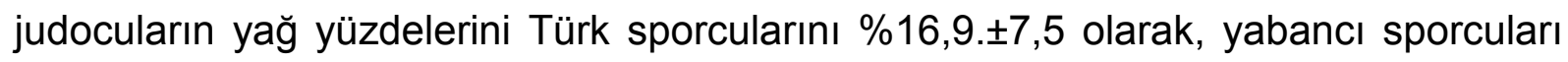

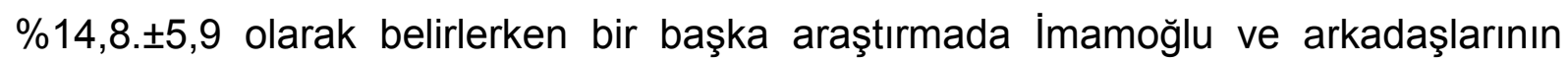
(1999) Türk judo Mili Takım sporcularının yağ yüzlerini \%8,7 olarak tespit etmiştir. Literatür bulguları bizim çalışmamızdan elde ettiğimiz değerlerler yakınlık göstermektedir.

Yapılan çalışmada haltercilerin sağ el el kavrama kuvvetleri 43.92 \pm 1.22 olarak bulunmuşken bu değer judocularda $46.47 \pm 1.57$ olarak tespit edilmiştir. Özsoy'un (2011) dövüş sporcularında yaptığı çalışmada sağ el el kavrama kuvvetini 46.1 \pm 10.5 , sol el el kavrama kuvvetini $44.2 \pm 13.9$ olarak tespit etmiştir. Bu değerlere bakıldığında bizim yaptığımız değerlere yakınlığı söz konusu olmasının nedeni bu tür sporlarda kavrama kuvvetinin önemli olduğunu ortaya koyduğu düşünülmektedir. Ayrıca çalışmada judocu ve haltercilerin elde edilen el-el kavrama rölatif kuvvet değerleri arasında anlamlı bir ilişki bulunamamıştır. Aydos ve arkadaşlarının (2004) içinde judo ve halter sporcularında bulunduğu toplam 7 spor branşının bazı fiziksel özelliklerini karşılaştırdığı çalışmada el-el kavrama rölatif kuvveti en yüksek değer ile 1.sırada halter sporcuları olduğunu belirtirken judo sporcularının el-el kavrama kuvveti bakımından 5. sırada olduğu gözlenmiştir.

Çalışmada haltercilere ait oksijen saturasyonu değerleri $96.09 \pm 0.19$ iken bu değer judocularda $95.42 \pm 0.27$ olarak tespit edilmiş ve halterciler yönünde anlamlı farklılık görülmüştür. Bunun sebebi oksijen saturasyon değerlerinin kişiden kişiye farklılık göstermesinden kaynaklandığını düşünmekteyiz. Yılmaz'ın (2018) elit judocularda yaptığı çalışmada oksijen saturasyon değerlerini ön testte $96.7 \pm 0.12$, son testte ise $97.52 \pm 1.12$ olarak bulmuştur. Bu değerler bizim yaptığımız çalışmaya benzer niteliktedir. Geleneksel yaşam bulguları vücut ısıSı, nabız, solunum ve kan basıncından oluşmaktadır. Son zamanlarda bu dört parametreye oksijen saturasyonu da eklenmiştir (Hakverdioğlu, 2007; Simon ve Clark, 2002). Genellikle cilt renginde herhangi bir değişiklik olmadan ve oksijen saturasyonu \%80-\%85.in altına düşmeden önce hipoksi belirlenememektedir (Giuliano ve Higgins, 2005). Yapılan çalışmamızda sporcuların herhangi bir hipoksi belirlenmemesi bulunan değerlerden anlaşılmaktadır. 
Sonuç olarak; yaptığımız çalışmada haltercilerin boylarının tekvando branşına göre kısa olması spor branşının kendine özgü bir özellik olmasından kaynaklanmaktadır. Ayrıca fiziksel ve fizyolojik parametrelerin bir birine yakın olmasın spor branşlarının kendi içinde sıkletlere ayrımasından kaynaklandığını düşünülmektedir. Yaptığımız çalışmada elde edilen veriler literatürdeki benzer çalışmalar ile karşılaştırıldığında veriler arasında benzerlik görülmüştür. Ancak önceki literatür tarandığında oksijen saturasyonu değerlerine pek rastlanmadığını, yaptığımız bu çalışmanın da bundan sonraki çalışmalara katkı sağlayacağı ve oksijen saturasyon ölçümlerinin de çalışmalara eklenebileceği düşünülmektedir.

\section{Kaynaklar}

Akın, G., Özder, A., Koca, B., \& Gültekin, T. (2004). Elit erkek sporcuların vücut kompozisyonu değerleri. DTCF Dergisi, 44(1),125-134.

Akkuş, H. (1994). Elit haltercilerin antropometrik özellikleri, biyomotor yetenekleri, fizyolojik özellikleri ve başarıları arasındaki ilişkilerin araştırıması, Marmara Üniversitesi Sağlık Bilimleri Enstitüsü Beden Eğitimi ve Spor Anabilim Dalı, Doktora Tezi, İstanbul

Aydos, L., Pepe, H., \& Karakuş, H. (2004). Bazı takım ve ferdi sporlarda rölatif kuvvet değerlerinin araştırılması. Gazi Üniversitesi Kırşehir Eğitim Fakültesi, 5(2), 305-315.

Aydın, M. (1997). Elit judocuların fizyolojik ve fiziki profili. Marmara Üniversitesi Sağlık Bilimleri Enstitüsü Beden Eğitimi ve Spor Anabilim Dalı, Yayınlanmamış Yüksek Lisans Tezi, İstanbul.

Boissy, P., Bourbonnais, D., Carlotti, M. M., Gravel, D., \& Arsenault, B. A. (1999). Maximal grip force in chronic stroke subjects and its relationship to global upper extremity function. Clinical rehabilitation, 13(4), 354-362.

Chumlea, W. C., \& Guo, S. S. (1994). Bioelectrical impedance and body composition: present status and future directions. Nutrition Reviews, 52(4), 123-131.

Claessens A., Beunen G., Simons J., Wellens R., Geldof D., \& Nuyts M. (1984). Body structure, somatotype and motor fitness of top class belgian judoists, Olympic Scientific Congress, Perspective in Kinanthropometry, vol 1, p 156. 
Çalışkan, D. (2007). Yetişkinlerde Biyoelektrik Empedans Analizi Ölçümleri ve Farkı Denklemlerle Karşılaştırılması, Hacettepe Üniversitesi Sağlık Bilimleri Enstitüsü,Yüksek LisanTezi,ss.8.

Esco, M.R., Snarr, R.L., Leatherwood, M.D., Chamberlain, N.A., Redding, M.L., Flatt, A.A., ... \& Williford, H.N. (2015). Comparison of total and segmental body composition using DXA and multifrequency bioimpedance in collegiate female athletes. The Journal of Strength \& Conditioning Research, 29(4), 918-925.

Fukuda, D. H., Stout, J. R., Moon, J. R., Smith-Ryan, A. E., Kendall, K. L., \& Hoffman, J. R. (2016). Effects of resistance training on classic and specific bioelectrical impedance vector analysis in elderly women. Experimental gerontology, 74, 9-12

Giuliano, K.K.,\&Higgins T.L. (2005). New-generation pulse oximetry in the care of critically ill patients. American Journal of Critical Care, 14 (1); 26-39.

Grap, M.J. (2002). Pulse oximetry. Critical Care Nurse, 22 (3), 669-674.

Hakverdioğlu, G. (2007). Oksijen Saturasyonunun Değerlendirilmesinde Pulse Oksimetre Kullanımı, C.Ü. Hemşirelik Yüksekokulu Dergisi, 11(3),45-49.

Harbili S, Hazır T, Hazır S., ŞAHIN, Z., HARBILII, E., \& AÇIKADA, C. (2008). Çocuk ve genç atletlerde vücut kompozisyonunun değerlendirilmesi: karşıllaştırma çalışması. Spor Bilimleri Dergisi, 19 (3), 181-202

İmamoğlu, O., Çebi, M., Kishalı, N.F., Tunç, T. (1999). Bayan Judo Milli Takım Sporcularında Bazı Antropometrik ve Fizyolojik Parametrelerin İncelenmesi, Atatürk Üniversitesi Beden Eğitimi ve Spor Bilimleri Dergisi,1(1)34-40.

İmamoğlu, O., Kishalı, N. F., Çebi, M., \& İmamoğlu, H. (2000). Türk judo erkek milli takımında vücut kompozisyonu parametrelerinin incelenmesi. Journal of Physical Education and Sport Sciences, 1(1).0-0

Kuru, E., \& Cicioğlu, İ. (2000). Türk erkek ve bayan judocuların vücut ağırlık merkezi ve vücut kompozisyonlarının yabancı judocularla karşılaştırıması. Gazi Beden Eğitimi ve Spor Bilimleri Dergisi.(4),28-34.

Küçükkubaş, N., Hazır, T., Açıkada, C. (2006). 15-17 Yaş ergen erkeklerde biyoelektrik impedans yönteminde ölçüm aralığının belirlenmesi. Spor Bilimleri Dergisi, 17 (2), 38-47. 
Leyk, D., Gorges, W., Ridder, D., Wunderlich, M., Rüther, T., Sievert, A., \& Essfeld, D. (2007). Hand-grip strength of young men, women and highly trained female athletes. European journal of applied physiology, 99(4), 415-421.

Lukaski, H. C., Bolonchuk, W. W., Hall, C. B., \& Siders, W. A. (1986). Validation of tetrapolar bioelectrical impedance method to assess human body composition. Journal of applied physiology, 60(4), 1327-1332.

MacAuley, D., McCrum, E., Evans, A., Stott, G., Boreham, C., \& Trinick, T. (1999). Physical activity, physical fitness and respiratory function-Exercise and respiratory function. Irish journal of medical science, 168(2), 119.

Miller, M. R., Hankinson, J. A. T. S., Brusasco, V., Burgos, F., Casaburi, R., Coates, A., ... \& Jensen, R. (2005). Standardisation of spirometry. European respiratory journal, 26(2), 319-338.

Nag, A., Nag, P. K., \& Desai, H. (2003). Hand anthropometry of Indian women. Indian Journal of Medical Research, 117, 260-269.

Ng, G. Y., \& Fan, A. C. (2001). Does elbow position affect strength and reproducibility of power grip measurements?. Physiotherapy, 87(2), 68-72.

Nunez, C., Gallagher, D., Spungen, A.Z., Bauman, W., \& Heymsfield, SB. (2003). Are age related bioimpedance analysis effects also present in patients with spinal cord injury? Relevance to clinical prediction of skeletal muscle mass. International Journal Of Body Composition Research 1, 11-16.

Özsoy, O.Ş.(2011). Taekwondo Branşında, Elit Düzey Poomseciler ve Dövüşçülerin Fiziksel ve Fizyolojik Değerlerinin Karşılaştırılması, Gazi Üniversitesi Sağlık Bilimleri Enstitüsü, Yüksek Lisans Tezi.

Pole, Y. (2002). Evolution of the pulse oximeter. International Congress Series,

Sarıtaş, N. (1995). Judocularda Kısa Süreli Kilo Kaybının Güç, Kuvvet, Dayanıkııık, Esneklik, Çeviklik Üzerine Etkileri, Erciyes Üniversitesi Sağlık Bilimleri Enstitüsü Yüksek İrtifa ve Spor Bilimleri, Yayınlanmamış Yüksek Lisans Tezi, Kayseri.

Siervogel, R.M., Demerath, E.W., Schubert, C., Remsberg, K.E., Chumlea, W.C., Sun, S., \& Towne, B. (2003). Puberty and body composition. Hormone Research in Paediatrics, 60 (Suppl. 1), 36-45. 
Simon, S.B., Clark, R.A. (2002). Using pulse oximetry: a review of pulse oximetry use in acute care medical wards. Clinical Effectiveness in Nursing, 6; 106 110.

Turnagöl, H. H., \& Demirel, H., (1992). Türk milli haltercilerinin somatotip profilleri ve bazı antropometrik özelliklerinin performansla ilişkisi. Spor Bilimleri Dergisi, 3(3),11-18.

Tutkun, E. (1996). Hentbol, Voleybol, Futbol, Güreş, Judo Okul Takımlarında Yer Alan Üniversite Öğrencilerinin Antropometrik Yapıları İle Motorsal Test Ölçümlerinin İncelenmesi. Ondokuz Mayıs Üniversitesi Sağlık Bilimleri Enstitüsü. Yayınlanmamış Yüksek Lisans Tezi, S, 53.

Yılmaz, T. (2018). Elit Judocularda Aerobik Antrenman Programının Kardiyopulmoner Parametreler ve Oksijen Saturasyonu Üzerine Etkisi, Gaziantep Üniversitesi Sağlık Bilimleri Enstitüsü, Yüksek Lisans Tezi.

Wang, Z., Deurenberg, P., Wang, W., Pietrobelli, A., Baumgartner, R. N., \& Heymsfield, S. B. (1999). Hydration of fat-free body mass: new physiological modeling approach. American Journal of Physiology-Endocrinology And Metabolism, 276(6),995-1003.

Watts, P. B., Joubert, L., Lish, A. K., Mast, J. D., \& Wilkins, B. (2003). Anthropometry of young competitive sport rock climbers. British journal of sports medicine, 37(5), 420-424. 